\title{
A study of stimulus generalization by the method of concurrent training
}

\author{
Laurence Stettner and Ronald Koteskey \\ WAYNE STATE UNIVERSITY
}

\begin{abstract}
Abstraet
Concurrent training is a proposed method for studying generalization by giving additional reinforced trials on new stimuli and assessing the effect on response strength to the training stimulus. Forty-seven rats run according to this method showed no difference in degree of generalization from alleys of white, light-gray, and dark-gray to black. Twenty-four rats run in the same apparatus by the usual procedure involving nonreinforced test trials d id show the expected decremental gradient.

Problem
\end{abstract}

The major purpose of this paper is to describe a new method for studying stimulus generalization and to compare results obtained by this method with results from standard techniques. The concurrent training method can best be described with the aid of Fig. 1. The top (B-O) and bottom (B-B) lines represent mean acquisition latencies for animals that received three and six reinforced daily trials respectively in a black alley. Suppose that we ran a group of animals which received three daily reinforced trials in a black alley plus three reinforced trials in a white alley, and then analyzed their performance in the black alley. The degree to which these B-W animals performed better than the B-O group would represent the contribution made to response strength in the black alley by the additional reinforced trials in the white alley. We can express the degree of this generalization as a percentage of the difference between the B-O and B-B groups, which represent anchor points of $0 \%$ and $100 \%$ generalization respectively. Thus, we can derive a generalization gradient without the nonreinforced test trials which are usually involved in investigations of stimulus generalization (cf., Mednick \& Freedman, 1960).

\section{Subjects}

The Ss were 71 male albino rats of the SpragueDawley strain, ca. 90 days old at the beginning of training. They were obtained from Rawley Farms, Plymouth, Michigan.

\section{Apparatus}

The apparatus consisted of four $8 \mathrm{ft}$ long straight alleys, equipped with jar-cap food cups at one end, all interior surfaces of which were painted either black, dark-gray, light-gray, or white respectively. (The darkgray was mixed from equal parts of Super Kemtone Latex wall paint No. 793 white and No. 751 black. The light-gray from one part black and five parts white.) Guillotine doors $1 \mathrm{ft}$ from either end of the alley delineated the start and goal boxes. A standard electric timer was activated by the raising of the start box door and switched off when the rat made contact with a wire grid 6 in in front of the food cup.

\section{Procedure}

Concurrent training. Following pre-training, during which time Ss were put on a 10-gm per day deprivation-feeding schedule and adapted to handling, each $\mathrm{S}$ was randomly assigned to one of five groups for 11 days of experimental training. There were $10 \mathrm{Ss}$ in each group save B-O, which had seven. B-O animals simply received three reinforced trials per day in the black alley. B-W animals had, in addition to three reinforced daily trials in the black alley, three reinforced daily trials in the white alley, in random order. B-LG and B-DG animals had their three additional daily trials in the light-gray and dark-gray alleys, respectively. Group B-B had six daily reinforced trials in the black alley.

Reinforcement consisted of a single "Frosty-O" pellet (a General Mills, Inc. sugar-coated breakfast cereal) on each trial. Running of Ss was rotated so that the intertrial interval (which $\mathrm{S}$ spent in his home cage) was $15 \mathrm{~min}$.

Standard generalization. Each $S$ was run for 10 days, six reinforced trials per day, in the black alley. On day 11, the animals were divided into three groups of eight each matched on the basis of alley speeds on the last four days of training. One group received six nonreinforced trials in the dark-gray alley on days 11 and 12, one was run in the light-gray alley and one in the white alley.

On day 13 , discrimination training commenced in order to determine independently if the alleys were, in fact, differentially discriminable from black. Each $S$ received three daily reinforced trials in the black alley and three unreinforced trials in the "other" alley to which it had been assigned on day 12. This training was continued for each $\mathrm{S}$ until it met a discrimination criterion of two consecutive days (12 trials) during which all latencies in the black alley were shorter than all latencies in the other alley.

\section{Results}

As indicated in Fig. 1, all generalization groups ran consistently faster than the B-O animals and consistently slower than the B-B animals, but there were no significant nor consistent differences found in black-alley speed between the B-W, B-LG, and B-DG groups $(\mathrm{F}=<1$ for difference between generalization groups over all 11 days and for the interaction between trials and 


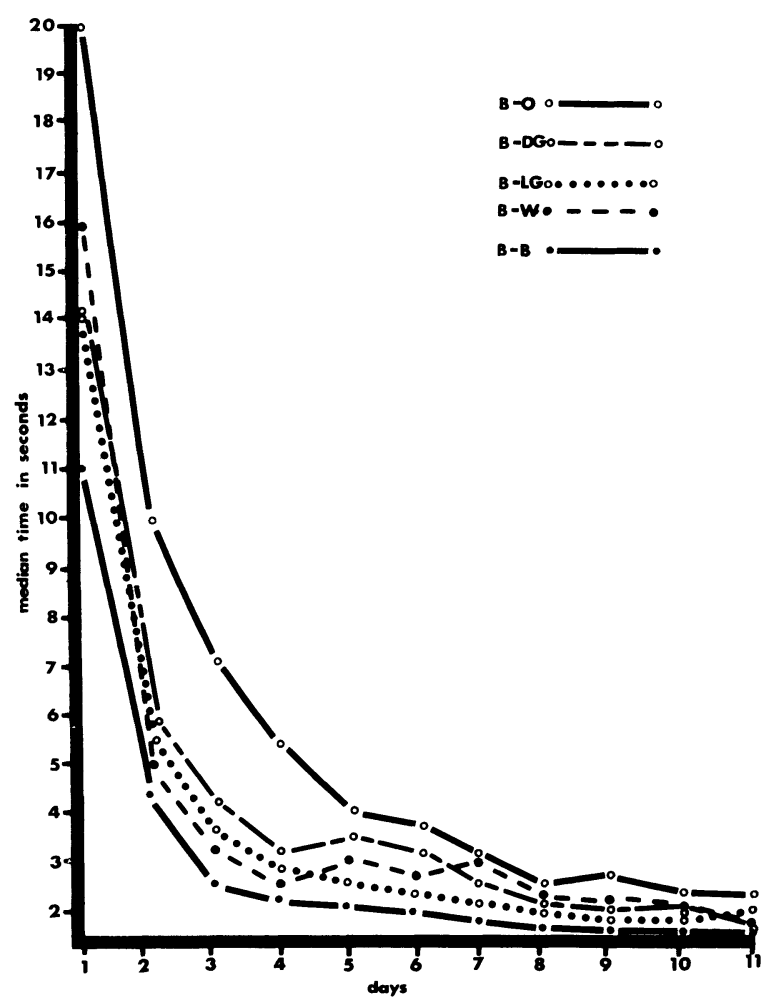

Fig. 1. Median running time in black alley.

generalization groups). The percentage of generalization for each three-day block of training is presented in Table 1 .

Note that the percentage generalization shows considerable stability over the course of training, even though the running times themselves were becoming markedly faster.

Median running times for the standard generalization tests on day 11 were $4.91,6.70$, and $14.92 \mathrm{sec}$. for the dark-gray, light-gray, and white alleys respectively, indicating a gradient of generalization according to degree of similarity in physical brightness to the black training alley $(\mathrm{F}=6.75 ; \mathrm{df}=2 / 21 ; \mathrm{p}<.01)$.

\section{Diseussion}

On the methodological side, the stability exhibited in the obtained percentages of generalization indicates that concurrent training is a reliable measurement technique. Concurrent training also provided information on the degree of generalization at different levels of training, right from the very first exposure to the
Table 1. Percentage Generalizations

$\begin{array}{rccccl}\text { Group } & 1-3 & 4-6 & 7-9 & 10-11 & \text { Mean } \\ \text { DG } & 77 \% & 75 \% & 69 \% & 71 \% & 75 \% \\ \text { LG } & 86 & 82 & 79 & 75 & 81 \\ \text { W } & 86 & 81 & 71 & 71 & 78 \\ \text { Mean } & 83 & 79 & 73 & 73 & 78\end{array}$

alleys. This would be exceedingly difficult and timeconsuming to obtain with standard generalization techniques.

Perhaps it might be argued that we should limit the term "generalization" to apply only to situations involving new, unreinforced stimuli. No such restriction appears, however, in basic theoretical notions about generalization. Hull (1943), for example, explicitly discussed the role of primary stimulus generalization in the summation of habit strengths among closely related stimuli which are all reinforced.

The concurrent training results present a problem in that we find neither some sort of gradual gradient (subject to a straight-forward explanation on the basis of physical stimulus similarity) nor a perfectly flat gradient (subject to possible interpretation on the basis of nonrelevance of the particular stimulus dimension manipulated by E), but rather a one-step gradient. These results may lend some credence to the suggestion by Prokasy \& Hall (1963) that we can account for decremental generalization gradients on the basis of "interfering responses" induced by the introduction of changed stimulus conditions. Such conditions were present when the usual gradient was obtained during the standard generalization test, but were not directly involved in the concurrent training measure. Any firm conclusions must, of course, await further use and comparison of the concurrent training method.

\section{References}

HULL, C. L. Principles of behavior. New York: Appleton-CenturyCrofts, 1943.

MEDNICK, S. A., \& FREEDMAN, J. L. Stimulus generalization. Psychol. Bull., 1960, 57, 169-200.

PROKASY, W. F., \& HALL, J. F. Primary stimulus generalization. Psychol. Rev., 1963, 70, 310-322. 